\title{
Conflito entre Evódia e Síntique (Fl 4,2): um antagonismo à comunidade ideal
}

\author{
The conflict between Euodia and Syntyche (Phil 4.2): An \\ antagonism to the ideal community \\ WALDECIR GONZAGA \\ VILSON JOSÉ DA SILVA (iDb
}

\section{Resumo}

Não é incomum encontrar uma comunidade eclesial que não tenha experimentado ou esteja experimentando problemas internos ou conflitos acirrados entre seus membros. Tais problemas, com toda a certeza, afetam, e muito, a vida da comunidade. No entanto, estes problemas não podem ser relativizados, ignorados e muito menos serem fatores de desagregação. À luz desta realidade, o presente artigo tem por objetivo enfatizar que, desde os primórdios da Igreja, os conflitos estão presentes no seu interior e que não é certo romantizar, de modo ingênuo, a vivência das primeiras comunidades a ponto de achar que lá não houvesse conflitos ou que tudo corria às "mil maravilhas", mas compreender, à luz destes acontecimentos, as comunidades e as relações de conflitos, que se estabelecem também no hoje da história e, tomando como referência a perícope de Fl 4,1-7, evidenciar como o apóstolo lidou com esta situação e quais foram as luzes jogadas sobre o problema e suas possíveis soluções.

Palavras-chave: Filipenses. Conflito. Evódia. Síntique. Igreja Primitiva.

\footnotetext{
a Pontifícia Universidade Católica do Rio de Janeiro (PUC-Rio), Rio de Janeiro, RJ, Brasil. Doutor em Teologia Bíblica, e-mail: waldecir@hotmail.com

b Pontifícia Universidade Católica do Rio de Janeiro (PUC-Rio), Rio de Janeiro, RJ, Brasil. Mestre em Teologia Bíblica, e-mail: vilson27js@yahoo.com.br
} 


\section{Abstract}

It is not uncommon to find an ecclesial community that has not experienced or is experiencing internal problems or intense conflicts among its members. Such problems, for sure, affect, and a lot, the life of the community. However, these problems cannot be relativized, ignored and even less disaggregating factors. In light of this reality, this article aims to emphasize that since the beginnings of the church, the conflicts are present in its internal and it is not right to romanticize, in a naive way, the experience of the first communities to the point of thinking that there, there were no conflicts or that everything was going "a thousand Wonders", but to understand, in light of these events, the communities and relations of conflicts, which are also established in today's history and, taking as a reference the pericope of the Phil 4:1-7, show how the apostle dealt with this situation and what lights were shed on the problem and its possible solutions.

Keywords: Philippians. Conflict. Euodya. Syntique. Early Church.

\section{Introdução}

Acerca da vida das primeiras comunidades cristãs, em At 2,42 se lê: “' Hoav

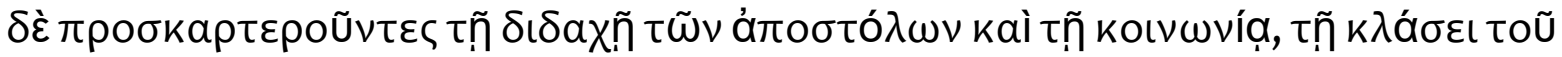

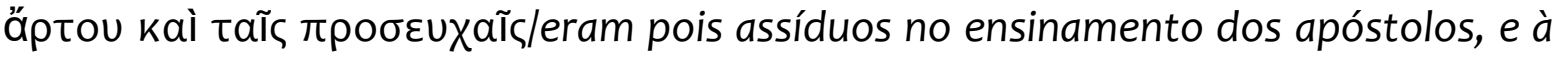
comunhão, à fração do pão e às orações". Como é possível entender esta afirmação se, nas cartas de Paulo, e também no próprio livro dos Atos dos Apóstolos, há referência muito clara a certos conflitos ${ }^{1}$ que, assim como hoje, não deixavam de interferir na vida da comunidade?

Um destes conflitos é o protagonizado por duas mulheres: Evódia e Síntique, descrito em Fl 4,2, que, provavelmente, ocupavam liderança ativa na vida da comunidade de Filipos, mas que estavam em desacordo uma com a outra. Diante disso, o apóstolo Paulo exorta-as à comunhão e à unidade por causa do vínculo comum que elas têm com o Senhor Jesus Cristo.

Se as comunidades viviam em paz e harmonia, como retrata o livro dos Atos dos Apóstolos, era de se esperar que Paulo não precisasse chamar ou convocar ninguém a viver na unanimidade do Senhor. Mas, se assim como hoje, tais

\footnotetext{
${ }^{1}$ Para maiores esclarecimentos sobre a temática conflitos na Igreja Primitiva, especialmente entre grupos como judaizantes e gentios, seja nas cartas paulinas, seja em Atos dos Apóstolos, indicamos duas obras: GONZAGA, 2015a; e GONZAGA, 2015b.
} 
divergências e desacordos aconteciam, isto não deve ser fator de desânimo para as atuais comunidades cristãs, mas sim motivo e incentivo para que se viva ainda mais o espírito de fraternidade e vida comum. Pois, o espírito de comunidade também passa pelo conflito, que é superado com caridade, perseverança e comum entendimento.

O objetivo deste artigo é enfatizar que não é certo romantizar, de modo ingênuo, a vivência das primeiras comunidades a ponto de achar que lá não havia conflitos ou que tudo corria às “mil maravilhas", mas de compreender, à luz destes acontecimentos, as comunidades e as relações de conflitos que se estabelecem também no hoje da história e vida da Igreja. Não é fugindo dos problemas que se resolve o conflito, muito menos mascarando, negando ou encobrindo as diferenças na vida comunitária.

Portanto, este artigo quer, de modo particular, apresentar como os conflitos aconteceram e como foram superados na Igreja Primitiva, e ter paradigmas para se buscar resolver os hodiernos, sem que os mesmos sejam ignorados ou relativizados. Outro desafio a ser superado também é que, diante dos conflitos, muitos tendem a querer abandonar a comunidade ou, pior ainda, a exigir uma comunidade de perfeitos, "santos e imaculados", esquecendo-se que as comunidades são formadas por humanos e não por anjos.

Para isto, será apresentada a tradução da perícope delimitada em Fl 4,1-7; notas de crítica textual, para fundamentar a tradução feita; breve comentário sobre alguns aspectos dos versículos, para iluminar a reflexão; uma aplicação pastoral para atualizar a metodologia utilizada por Paulo e algumas considerações finais. No entanto, não se entrará na problemática da composição da carta, isto é: autoria, datação, destinatários, composição, se a mesma é formada por um ou mais bilhetes, e sequer em temáticas gerais do corpus paulinum (GONZAGA, 2017, p. 19-41). 


\section{Texto, segmentação e tradução Fl 4,1-7}

Quadro 1 - Texto, segmentação e tradução Fl 4,1-7²

\begin{tabular}{|c|c|c|}
\hline 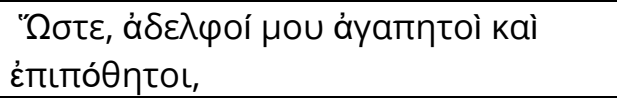 & $1 a$ & $\begin{array}{l}\text { Portanto, meus irmãos amados } \\
\text { e saudosos, }\end{array}$ \\
\hline 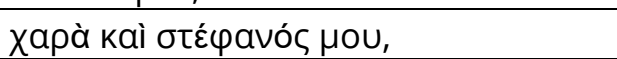 & $1 \mathrm{~b}$ & minha alegria e coroa, \\
\hline 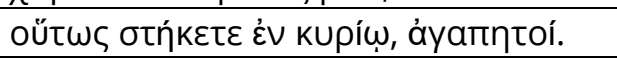 & $1 \mathrm{c}$ & assim permanecei no Senhor, amados. \\
\hline 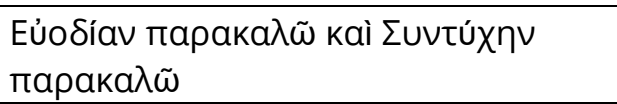 & $2 a$ & Exorto Evódia e exorto Síntique \\
\hline 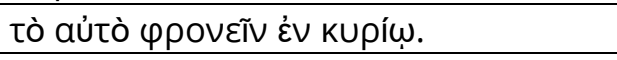 & $2 \mathrm{~b}$ & a pensarem o mesmo no Senhor \\
\hline 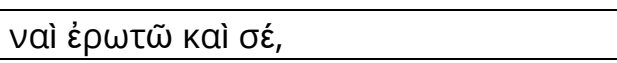 & $3 a$ & Sim, peço também a ti, \\
\hline 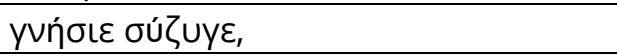 & $3 b$ & verdadeiro companheiro de jugo, \\
\hline$\sigma u \lambda \lambda a \mu \beta a ́ v o u$ aủtaĩ & $3 c$ & auxilie a elas \\
\hline 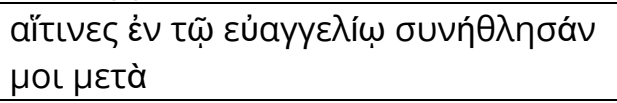 & $3 d$ & $\begin{array}{l}\text { as quais, no evangelho, combateram junto } \\
\text { comigo }\end{array}$ \\
\hline 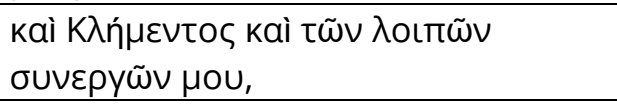 & $3 e$ & e Clemente e os meus demais colaboradores, \\
\hline 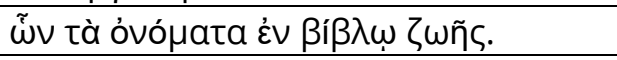 & $3 f$ & os quais, os nomes, estão no livro da vida. \\
\hline 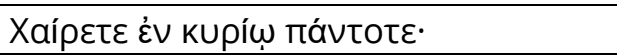 & $4 a$ & Alegrai-vos sempre no Senhor! \\
\hline 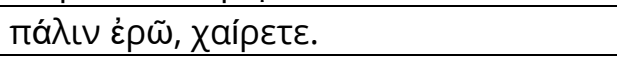 & $4 \mathrm{~b}$ & Novamente digo: alegrai-vos! \\
\hline 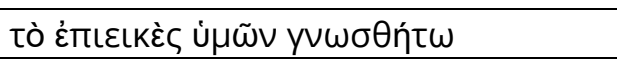 & $5 a$ & Vossa benevolência seja conhecida \\
\hline 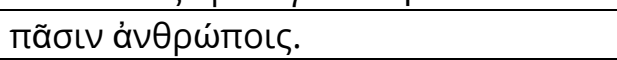 & $5 b$ & (diante) de todos os homens, \\
\hline ó kúpıos દ̇yyúç. & $5 c$ & (pois) o Senhor (está) próximo. \\
\hline$\mu \eta \delta \grave{\varepsilon} \vee \mu \varepsilon \rho \iota \mu \nu \tilde{\alpha} \tau \varepsilon$, & $6 a$ & Não vos preocupeis, \\
\hline 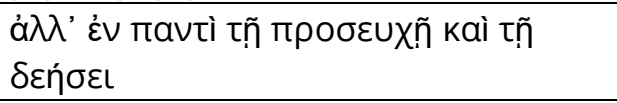 & $6 b$ & mas em toda oração e súplica, \\
\hline 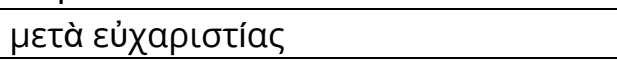 & $6 c$ & com ação de graça \\
\hline 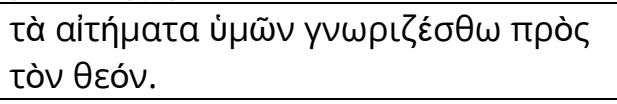 & $6 d$ & $\begin{array}{l}\text { os vossos pedidos sejam conhecidos junto a } \\
\text { Deus. }\end{array}$ \\
\hline 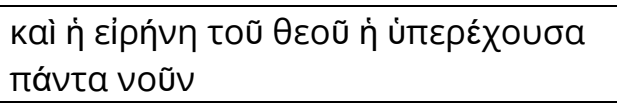 & $7 a$ & $\begin{array}{l}\text { E a paz de Deus, que ultrapassa todo } \\
\text { conhecimento, }\end{array}$ \\
\hline 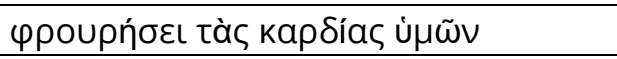 & $7 \mathrm{~b}$ & guardará os vossos corações \\
\hline 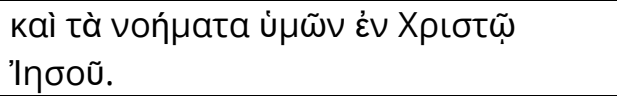 & 7c & e as vossas mentes em Cristo Jesus. \\
\hline
\end{tabular}

Fonte: O autor.

\footnotetext{
2 Os textos gregos aqui usados neste artigo são extraídos de Nestlé-Aland (2012), seja para este quadro, seja para as palavras ao longo do artigo. Esta tabela foi elaborada pelos autores do artigo, que também fizeram a tradução do texto, do grego para o português.
} 


\section{Crítica Textual}

No v.1c, o Manuscrito B, o minúsculo 33 e a versão siríaca propõem a

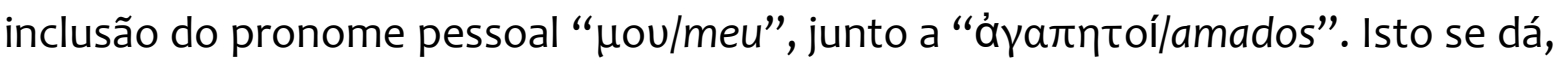
provavelmente, para harmonizá-lo com o v.1a. Os ocidentais $D^{*}$ ar b vg'mss omitiram

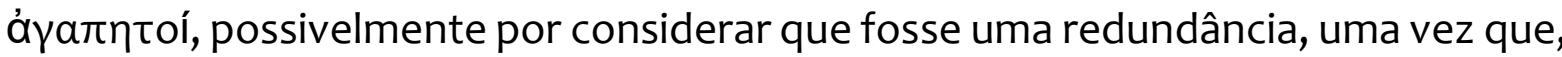

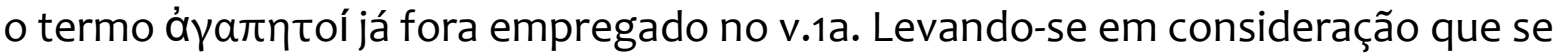
deva considerar que lectio difficilior preferenda est (GONZAGA, 2015C, p. 221), opta-

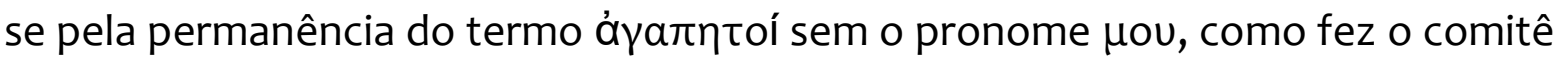
da Nestlé-Aland, $28^{\mathrm{a}}$ edição.

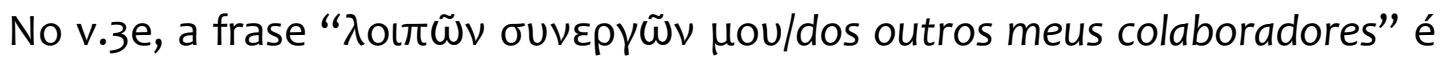

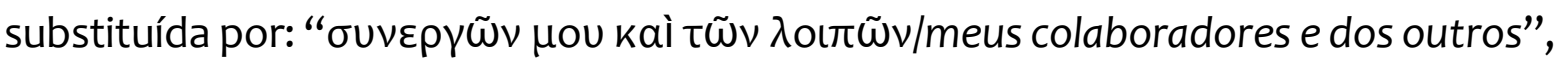
no papiro $\mathfrak{P}^{16 v i d} \kappa$. Apesar de o Papiro e o Manuscrito sinaítico serem testemunhos de peso para a Carta aos Filipenses, tal substituição em nada afeta o entendimento do texto, e se apresenta como uma lectio corrigenda (GONZAGA, 2015C, p. 221) ou um “descuido do escriba”. Por isso, opta-se pela sua permanência como sendo a melhor leitura para o texto, seguindo o comitê da Nestlé-Aland, $28^{a}$ edição.

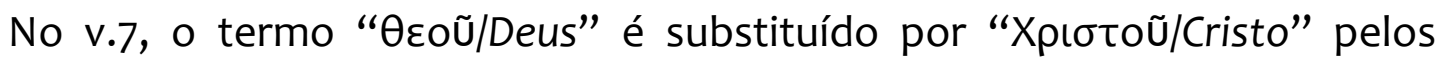
Manuscritos A t vg ${ }^{\mathrm{mss}} \mathrm{sy}^{\mathrm{hmg}}$. Muito provavelmente, tal substituição ocorreu pela interpretação do copista em harmonizar o texto com $\mathrm{Cl}_{3,15}$, que também emprega

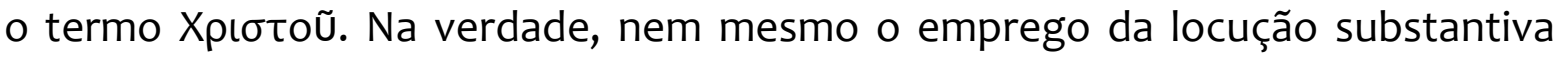

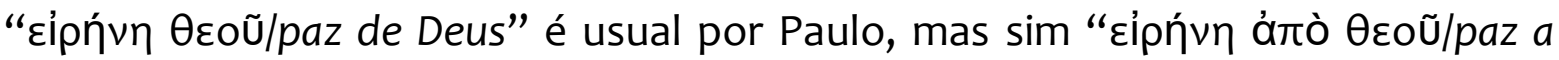
partir de Deus" (cf. Rm 1,7; 1Cor 1,3; 2Cor 1,2; Gl 1,3; Ef 1,2; 6,23; Fl 1,2; Cl 1,2; 2Ts 1,2; 1Tm 1,2; $2 \operatorname{Tm} 1,2 ; \operatorname{Tt~1,4;~Fm~1,3).~Deste~modo,~pela~variante~apresentar-se~como~uma~}$ lectio harmonizata (GONZAGA, 2015C, p. 221), opta-se pela permanência do termo Өદoũ, concordando com o comitê da Nestlé-Aland, $28^{\mathrm{a}}$ edição.

Ainda no v.7, os Manuscritos F G ar d; MVict Pel ao invés de lerem

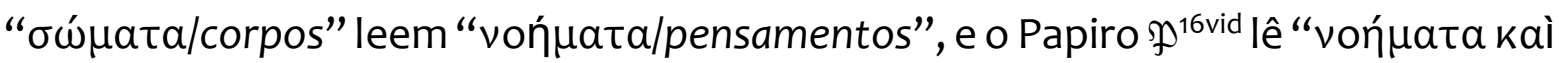

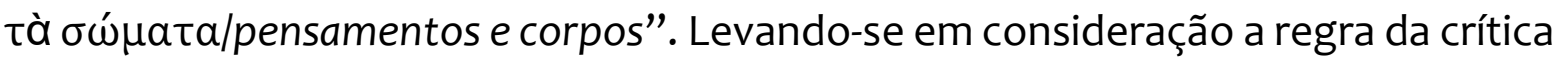
interna, lectio brevior preferenda est, em detrimento da lectio facilior (GONZAGA, 2015c, p. 221), e o fato de que os demais Manuscritos testemunham em favor do texto (txt), opta-se por manter a leitura que fez o comitê da Nestlé-Aland, $28^{a}$

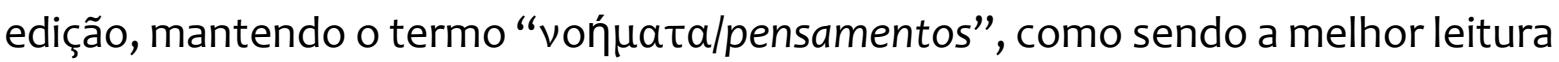
para o texto. 


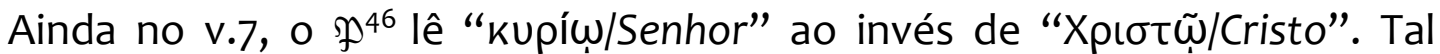
substituição, com muita probabilidade, ocorreu por uma harmonização textual, pois o termo "kupíw/Senhor" se repete nos vv.1c.2b.4a. Considerando-se que a

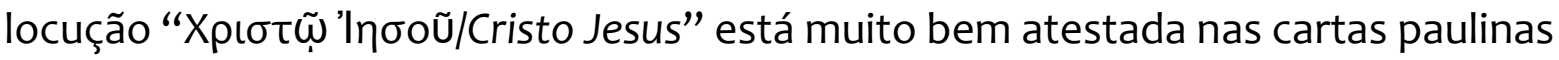
e por apresentar-se como uma harmonização, opta-se pela permanência do termo

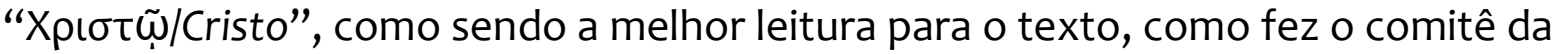
Nestlé-Aland, $28^{\text {a }}$ edição.

\section{Estrutura literária e delimitação}

Os comentadores, em sua grande maioria, a exemplo de Tomlin (2015, p. 145-168) e Bianchini (2010, p. 84-89), veem a unidade da seção estabelecida entre os vv.2-23, estando esta unidade dividida em duas partes vv.2-9 e vv.10-23 e o v.1 fazendo parte da seção maior 3,1-4,1; Cousar (2001, p. 178) estende esta seção até 4,3. Para se estabelecer a estrutura desta perícope conta muito o desenvolvimento formal-conteudístico que está presente no texto bíblico. Este texto trata da unidade da Igreja e dos dons para o serviço em prol desta unidade. Colaboram para tanto a terminologia, as repetições, as inclusões, o quiasmo e os paralelismos.

A proposta desta pesquisa é a de considerar a delimitação da perícope em 4,17, assim como apresentam Cabral (2015, p. 119-129) e Hahn e Mitch (2018, p. 35) em seus estudos, pois mesmo que 4,1 possa ser considerado, estritamente, como a conclusão da narrativa iniciada em 3,1, como pensa Bianchini (2010, p. 84), é preciso ponderar que os versículos que se seguem, a partir de 3,2 até 3,21, não formam a continuação lógica da exortação iniciada em 3,1 (BARTH, 1983, p. 61), mas fariam parte de um outro bilhete, tema este que não será trabalhado neste artigo.

Mazzarolo (2011, p. 146), auxilia na delimitação, ao dizer: "ainda que na abertura [4,1]3 não apareça o lexema ‘to loipón' como em 3,1 e 4,8 [o qual é a marca para o final de uma exortação] ${ }^{4}$ pode-se presumir que o objetivo é um último conselho". Além do que, há a possibilidade de se considerar o v.1 como um versículo ponte/dobradiça, como adverte Penna (2002, p. 125), ou de "versículo de transição", pois o mesmo está funcionando como elemento de retransmissão

\footnotetext{
${ }^{3}$ Grifo nosso.

${ }^{4}$ Grifo nosso.
} 
entre o que foi dito e o que se segue. O'Brien (1991, p. 482) e Hansen (2009, p. 278), mesmo considerando a unidade até o v.9, corroboram ao afirmar que a conjunção

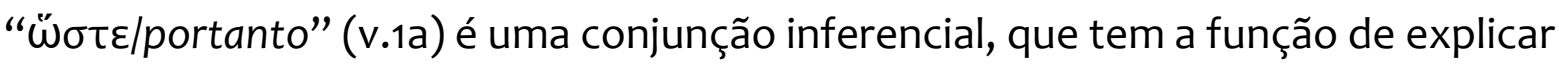
o que está sendo dito anteriormente, isto é, em 3,17-21.

Os vv.8-9, mesmo estando dentro desta unidade temática, trazem os motivos pelos quais os cristãos devam agir tendo como exemplo a Paulo e seu modus vivendi et operandi (BIRD; GUPTA, 2020, p. 170). Estes versículos, portanto, podem ser considerados como uma subunidade, pois apresentam exortações finais, introduzidas pela expressão "finalizando" (BARTH, 1983, p. 82.84). E, como adverte Cabral (2015, p. 130), o v.7 é uma espécie de conclusão, além de que os vv.10-20, de acordo com Silva (2005, p. 220), estariam fora de lugar.

\section{Comentário sobre os versículos}

Os amados, alegria e coroa de Paulo, são chamados a permanecer no Senhor (v.1)

No v.1 destacam-se cinco vocativos enfáticos empregados por Paulo (FEE, 2004, p. 484), os quais estão sendo utilizados literalmente em função do convite

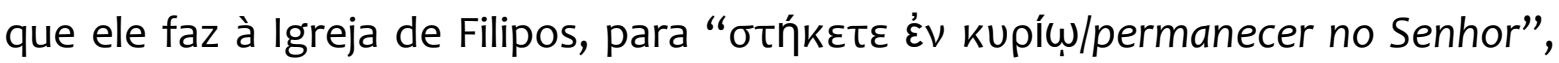
como em Ef 3,17, vencendo as provações, com admoestação carinhosa e firme (MARTIN, 2011, p. 165; FOCANT, 2016, p, 258; PÉREZ MILLOS, 2016, p. 278). Seu comportamento é o de um pastor prudente e preocupado com seu rebanho, capaz de tratar a todos com carinho e amor, visto que "os filipenses são a alegria do coração do apóstolo" (HENDRIKSEN, 2005, p. 574).

Portanto, ao elencar as características dos filipenses, dizendo que eles são:

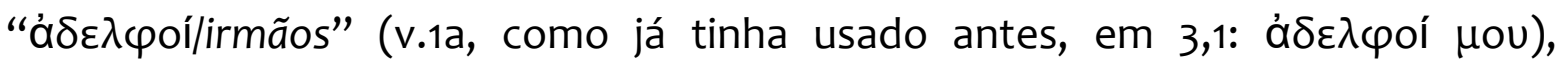

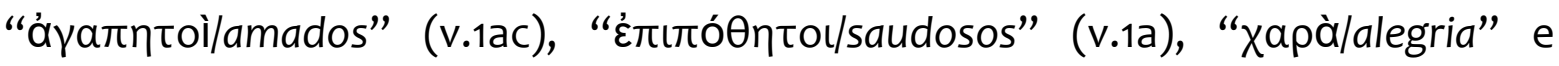

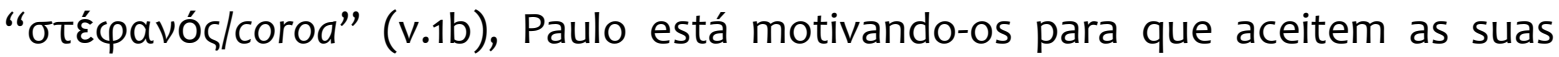
interpelações. Ele faz isso com um amor que transborda em carinho e respeito "em relação ao rebanho que Deus Ihe confiara" (PÉREZ MILLOS, 2016, p. 279). Com este gesto afetuoso, antes de exortar os membros da Igreja de Filipos para que possam

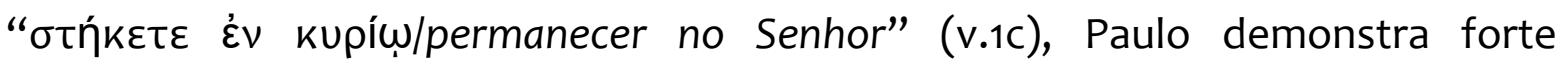
aproximação e grande afeição por eles (HANSEN, 2009, p. 279; PASTOR, 2005, p. 41; SCHLIER, 1973, p. 282). Isso é evidenciado pelos dois vocativos presentes neste 


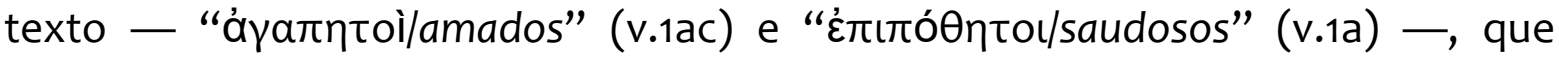
revelam quão intenso era esse amor (PENNA, 2002, p. 125).

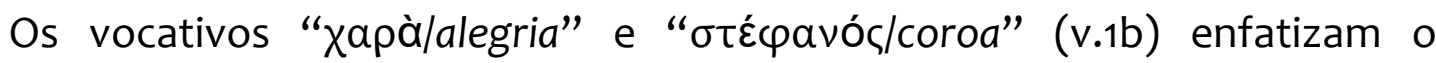
transbordamento deste amor que fora anteriormente declarado, pois o termo "coroa" constitui-se o prêmio e o sinal de honra do atleta vencedor (cf. 1Cor 9,25; $2 \operatorname{Tm~4,8;~} \operatorname{Tg} 1,12 ; 1 \mathrm{Pd}$ 5,4; Ap 2,10; 3,11; 4,4.10, entre outros). Por isso, a "coroa" pode ser o símbolo da recompensa dada a quem permaneceu firme no Senhor, até o último dia, como apresenta 1Ts 2,19, uma vez que se iguala à "coroa" de Cristo (cf.

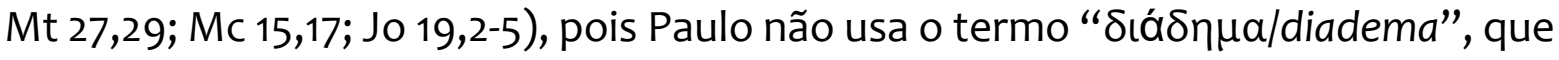

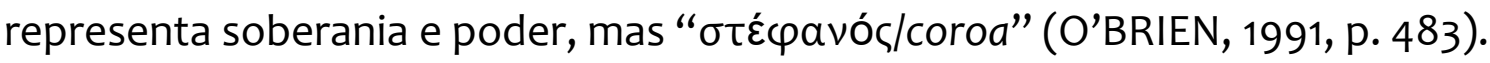

Portanto, ao se referir deste modo aos filipenses, muito provavelmente Paulo esteja dizendo: que isto será uma realidade na escatologia, embora já seja algo concreto no presente. Por conseguinte, aqui reside a necessidade de "permanecer firmes" no Senhor (HAWTHORNE; MARTIN, 2004, p. 241). Por isso, Paulo usa este caráter mais "exortativo e parenético" nesta parte da Carta aos Filipenses (PASTOR, 2005, p, 41), o que, aliás, "é comum em grande parte das cartas paulinas, nas quais o redator recolhe uma série recomendações finais para seus destinatários" (PITTA, 2010, p. 275), por meio do emprego de verbos no imperativo, dando o tom ao texto, visto que "os mesmos têm sua própria lógica" (FEE, 2004, p. 501-505) e levam consigo uma "longa série de apelativos" (HAWTHORNE; MARTIN, 2004, p. 239), que o apóstolo quer transmitir a Evódia e Síntique e à comunidade toda. Tais recomendações têm a finalidade de sustentar a vida dos membros da comunidade (SCHLIER, 1973, p. 280).

Evódia e Síntique chamadas a viver em harmonia no Senhor, para evidenciar a unidade do Evangelho (v.2)

Evódia e Síntique são chamadas a viver em harmonia no Senhor (FEE, 2004, p. 490; REUMANN, 2008, p. 626), pois elas têm vivido "em desavença" (MARTIN, 2011, p. 166) e não segundo "os princípios de paz e harmonia que devem reger a vida cristã" (PÉREZ MILLOS, 2016, p. 275). O autor não tem dúvidas de que a igrejacomunidade precisa viver a unidade na diversidade (PASTOR, 2005, p, 41).

Segundo Hawthorne e Martin, o apelo paulino é para que Evódia e Síntique “concordem uma com a outra no Senhor" (2004, p. 231). Por isso, Paulo "roga pela paz entre Evódia e Síntique” (ODEN, 2001, p. 337). Mais ainda, em momento algum 
Paulo teve como intenção "fustigar publicamente a estas duas colaboradoras" (FOCANT, 2016, p, 263). Segundo Penna (2002, p. 126), não há dúvida de que este versículo está repetindo o que fora dito no v.1, sendo, de modo particular, uma aplicação concreta dele. Porém, embora Paulo fale de um desacordo entre as duas, ele não menciona qual era e muito menos o motivo, ficando quase que "impossível para nós saber a natureza do desacordo entre Evódia e Síntique" (FEE, 2004, p. 497), pois ele apresenta apenas as exortações e não a indicação da causa do desacordo (HOLLOWAY, 2017, p. 182).

De todos os modos, segundo Craddock (2015, p. 73) e Fee (2004, p. 488), Paulo menciona publicamente o nome das duas, em uma carta a ser lida publicamente na comunidade, não porque as vê como inimigas. Pelo contrário, porque são amigas de caminhada e porque ele tem esperança de que a própria comunidade ajude a resolver o problema. Isso também indica que elas tinham liderança diante da comunidade (FOCANT, 2016, p, 263), mas que, com o desentendimento entre elas, estavam sendo um mau exemplo para a Igreja. Com esta atitude e gesto, de rogar a ambas para que mudem seu comportamento, Paulo "nos dá um novo exemplo de como pastoralmente se deve afrontar um problema na Igreja" (PÉREZ MILLOS, 2016, p. 281), indicando que cada uma devia dar um passo em direção à outra a fim de se resolver as dificuldades em vista do bem de ambas e de toda a comunidade. A conduta pessoal traz implicações para a vida comunitária.

De acordo com Bianchini (2010, p. 85), Evódia e Síntique são nomes muito difundidos nos séculos I-II d.C. Hansen (2009, p. 282) acrescenta que os mesmos aparecem em inscrições de túmulos do primeiro século, bem como são atribuíveis tanto a homens como a mulheres. A mesma ideia encontra-se em Pitta (2010, p. 275), que, porém, defende que "eram mais frequentes em mulheres". No entanto, como o texto apresenta o artigo definido feminino, então, de fato, estão se referindo a duas mulheres. Até mesmo porque, sendo "nomes comuns" para a época e região (MARTIN, 2011, p. 166), o mais comum era seu uso "na forma feminina" (HAWTHORNE; MARTIN, 2004, p. 241). Segundo Reumann, Evódia e Síntique deviam ser duas mulheres "muito engajadas na causa do Evangelho" (2008, p. 625), e Clemente e outros deviam ser parceiros fiéis de caminhada na vida comunitária.

O interessante é que os dois nomes (Evódia e Síntique) são mencionados

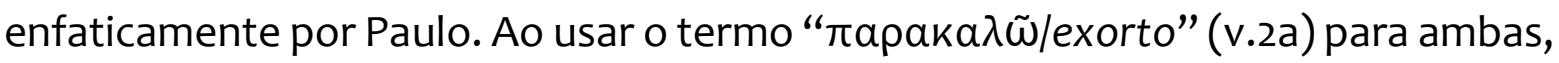


ele demonstra que não tomou partido por nenhuma delas (HANSEN, 2009, p. 282), tratando-as "em pé de igualdade" (FOCANT, 2016, p. 264). Ao convocá-las, o autor sugere que Evódia e Síntique eram importantes na vida e estrutura da comunidade (LLAGUNO, 2008, p. 727), a exemplo também de Lídia, segundo o texto bíblico de At 16,14-15.40 (FOCANT, 2016, p. 263; REUMANN, 2008, p. 626). Mas, quem eram elas: Seriam diaconisas? Segundo Silva (2005, p. 221) seria muito improvável. Teriam bens (LÓPEZ, 2019, p. 12) que pudessem ajudar na estrutura e organização da Igreja como sugerem os nomes? Conforme Mazzarolo (2011, p. 158-159), os dois nomes indicam "fortuna e sucesso".

Ou ainda, seriam os nomes aqui uma referência aos dois grupos presentes na Igreja Primitiva: os judeu-cristãos e os gentios-cristãos, como pensa a escola de Tübingen? Segundo O'Brien (1991, p. 486), Martin (2011, p. 166) e Hendriksen (2005, p. 576), isso não deve ser levado em consideração. Seria o nome de Evódia uma abreviação do nome Lídia? (MAZZAROLO, 2011, p. 158). Não se tem base o suficiente para afirmar isso. Também não há base neste texto para falar que Evódia e Síntique eram "líderes de partidos anti ou pró-paulinos" (FOCANT, 2016, p. 263). $O$ certo é que Paulo as exorta publicamente para que "tenham o mesmo sentir-se no Senhor" (ODEN, 2001, p. 338) e não continuem causando desavenças na vida da comunidade, pelo contrário, contribuam para o bem das mesmas e dos demais.

Quaisquer que sejam as deduções, a única certeza que se tem é de que elas tinham liderança frente à comunidade e que o conflito vivido por elas atingiu a todos os demais ou que levava a comunidade a afastar-se da unidade com o Senhor. E se Paulo se dirige a elas distintamente é porque a discordância entre elas não era apenas um assunto pessoal e também não era um problema teológico doutrinário. Se assim o fosse, Paulo teria mencionado. Sem dúvida, era algo que dizia respeito a todos e, como advertem Bird e Gupta (2020, p. 172), se Paulo procedeu deste modo, isto significa que toda a Igreja, ao tomar conhecimento, devia assumir a responsabilidade por este chamado à unidade do Evangelho. Segundo O'Brien

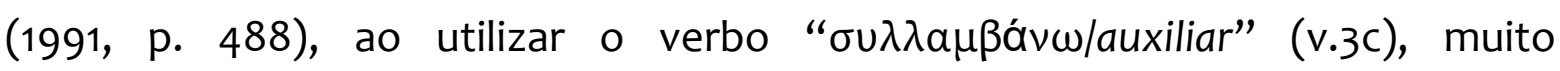
provavelmente as duas já estavam tentando superar o conflito.

O verdadeiro companheiro de jugo é chamado a ser um mediador (v.3) 


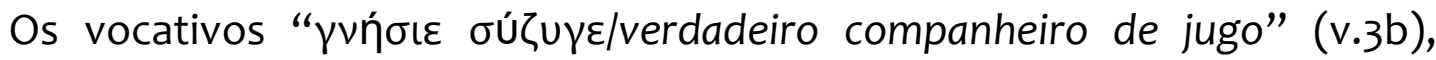
empregados por Paulo nesta perícope, têm causado grandes discussões entre os

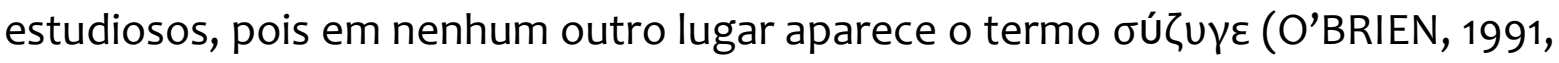

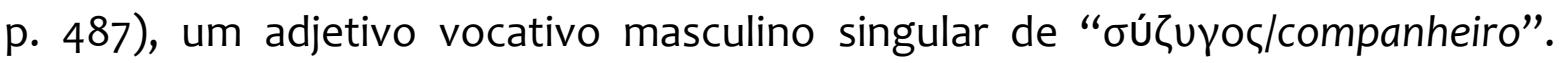
Segundo Pitta (2010, p. 278) e Reumann (2008, p. 628.631), Paulo espera encontrar apoio neste companheiro a fim de ajudar a contornar o problema que está acontecendo na vida da comunidade, especialmente entre Evódia e Síntique. Neste sentido, "Sízigo" entra como "um fiel colaborador" de Paulo (CRADDOCK, 2015, p. 74; ODEN, 2001, p. 337-338; FEE, 2004, p. 493), na perspectiva de indicar um “companheiro genuíno” ou um “cooperador fiel” (PÉREZ MILLOS, 2016, p. 283; HOLLOWAY, 2017, p. 182; HAWTHORNE; MARTIN, 2004, p. 242). Etimologicamente,

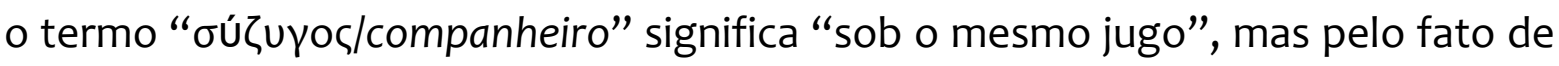
ser um termo único, segundo Bianchini:

Alguns autores [sem citar quais] ${ }^{5}$ levantam a hipótese de que é um nome próprio, mas esse uso não é atestado na época de Paulo; portanto, é melhor considerar o termo no sentido de "companheiro", referindo-se a um colaborador do Apóstolo envolvido na vida da Igreja de Filipos e, por isso, bem conhecido pela comunidade (BIANCHINI, 2010, p. 85).

Na opinião de Gnilka (1972, p. 282), mesmo que não se possa atestar documentalmente este nome, não se deve excluir a sua existência real, pois somente por ser um nome real é que a comunidade poderia, com efeito, entender quem seria "esta pessoa" que tinha a tarefa de resolver a disputa entre Evódia e Síntique. E ainda, de acordo com Gnilka (1972, p. 283), o “máximo da especulação exegética” foi identificar este "companheiro de jugo" com Lídia, a qual seria casada com Paulo, pois o termo jugo também pode referir-se "ao/à esposo/a", tomando como referência o latim “con-iux/jugo", no sentido de "junto". Mas esta não é uma questão tão simples, pois 1 Cor 7,8 atesta que Paulo não era casado (PENNA, 2002, p. 130).

Mesmo respeitando a conotação literal do termo " $\gamma \nu \eta ́ \sigma \iota \varepsilon$

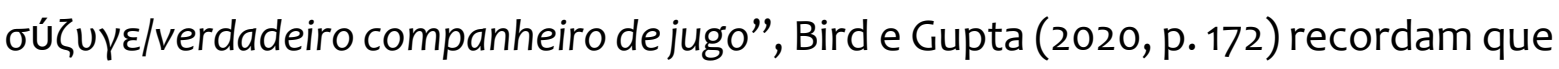
tal termo se refere a alguém e este alguém pode ser Silas, Lucas, Timóteo ou um

\footnotetext{
${ }^{5}$ Grifo nosso.
} 
líder local, visto que estes foram identificados como companheiros de missão, mas que, segundo eles, o nome mais apropriado seria Epafrodito, o portador da carta.

Sendo um nome próprio "Sízigo", algo difícil de se comprovar (MARTIN, 2011, p. 168; FOCANT, 2016, p, 266), ou uma característica de alguém inominado "verdadeiro companheiro", este tem a missão de intermediar no conflito e de

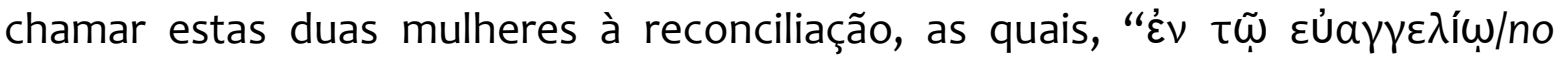

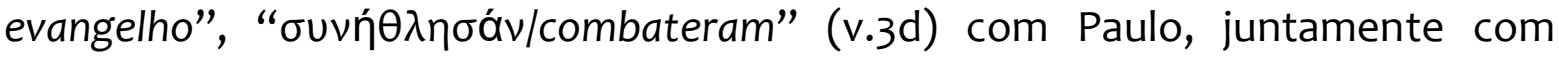

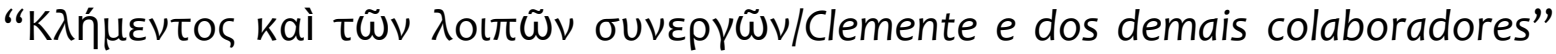
(v.3e). Segundo Focant, o melhor é interpretar "Sízigo" como um "simples apelativo para indicar um companheiro de trabalho cuja sinceridade é algo que sobressai" (2016, p. 266). Neste sentido, Hendriksen (2005, p. 576) afirma que Paulo está se referindo a um "fiel companheiro", que fazia parte desta comunidade, indicando-o como um amigo fiel. Por isso mesmo, tem seu nome " $\varepsilon$ v $\beta i ́ \beta \lambda \omega \zeta \omega \tilde{n} \varsigma /$ no livro da vida" (v.3f). Clemente, nome de raiz latina, "devia ser alguém conhecido na comunidade de Filipos" (FOCANT, 2016, p, 265). Segundo Pitta (2010, p. 279-280), Craddock (2015, p. 74) e Hawthorne e Martin (2004, p. 243), por ser um nome difuso no mundo latino antigo, não é fácil estabelecer quem seria este Clemente.

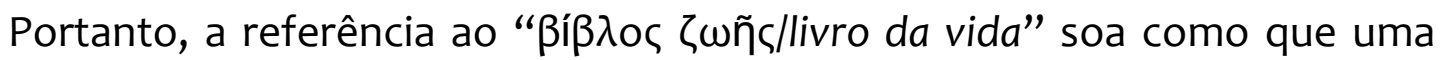
nota escatológica, referente à "vida eterna" (PÉREZ MILLOS, 2016, p. 286; FEE, 2004, p. 484-486; REUMANN, 2008, p. 634), consoante com a lembrança da cidadania no céu $(\mathrm{Fl} 3,20)$. Desta maneira, sendo eles cidadãos de Colônia romana, que têm seus nomes registrados em registro cívico de cidadãos, sabem que têm o dever de viver em harmonia e paz uns com os outros, visto que "a paz alimenta e proporciona uma harmonia perfeita" (ODEN, 2001, p. 337). Do mesmo modo, ao terem seus nomes escritos " $\varepsilon \dot{v} \vee \beta i ́ \beta \lambda \omega \zeta \omega n ̃$ /no livro da vida", são chamados por seu Senhor acima de todos os poderes, para viver em paz uns com os outros (HANSEN, 2009, p. 286).

Chamados a alegrar-se sempre no Senhor e a reconhecer que o Senhor está próximo (v.4-5)

Nos versículos anteriores, Paulo dirigiu-se a pessoas em particular; agora ele fala a toda comunidade e, por duas vezes, o apóstolo emprega a forma verbal no

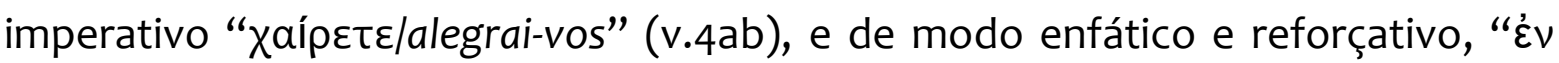


kupíw/no Senhor" (REUMANN, 2008, p. 634), quase como que uma "determinação” (HAWTHORNE; MARTIN, 2004, p. 244), indicando "o objeto e a causa do gozo" (FOCANT, 2016, p. 268), que se obtém apenas se se permanece firme no Senhor (PÉREZ MILLOS, 2016, p. 279).

O convite de Paulo é para que se esteja em reiterada alegria (CRADDOCK, 2015, p. 75), como contínuo princípio de vida e "sempre no Senhor" (MARTIN, 2011, p. 168), ratificando que a alegria deve ser uma característica permanente entre os irmãos e irmãs, na vida comum e fraterna. Por isso, insiste repetindo o imperativo

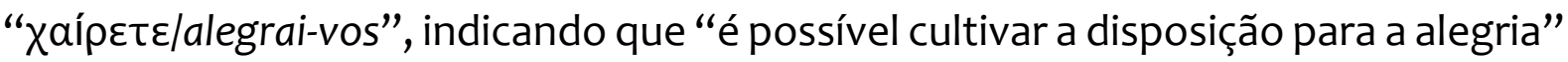
(HENDRIKSEN, 2005, p. 578). Ele o faz porque a alegria é antidoto saudável para qualquer desentendimento, seja ele pessoal ou comunitário. Por essa razão, Paulo está insistindo que a harmonia, tanto a pessoal quanto a comunitária, deve retornar ao seu equilíbrio (PENNA, 2002, p. 130). O v.4ab comporta um quiasmo, perceptível tanto no grego como no português, com um duplo imperativo

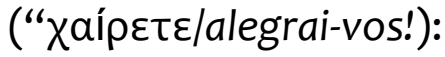

Quadro 2 - Quiasmo v.4ab

\begin{tabular}{|c|c|c|}
\hline 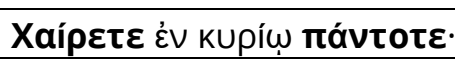 & $4 a$ & Alegrai-vos no Senhor sempre! \\
\hline 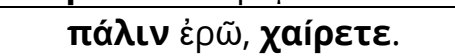 & $4 \mathrm{~b}$ & Novamente digo: alegrai-vos! \\
\hline
\end{tabular}

Fonte: Nestlé-Aland (2012).

Este chamado à alegria tem como pano de fundo a própria situação de Paulo, mesmo diante de tantos sofrimentos e prisões (REUMANN, 2008, p. 634). Aliás, como é sabido, esta Carta aos Filipenses foi escrita dentro de uma das prisões que Paulo sofrera (cf. Fl 1,13-14; Ef 3,1-13; 4,1, entre outros). Mas ele não se cansava de render graças a Deus e entoar hinos e cânticos, transformando os seus sofrimentos em oferendas a Deus (cf. Ef 3,14-19), dando um sentido a este sofrimento (MARTIN, 2011, p. 169). Entretanto, sua grande razão deve ter sido a própria tristeza causada pelo comportamento de Evódia e Síntique, que deve ter contagiado a todos, causando desânimo e tristeza entre os membros da comunidade (PÉREZ MILLOS, 2016, p. 286).

Os filipenses, sabedores da prática paulina de tudo bendizer e de se alegrar (cf. 1Ts 5,16), ao ouvir esta exortação à alegria, têm consciência de que Paulo está 
convidando-os a se alegrarem com tudo o que o Senhor fez, está fazendo e fará em benefício dos seus (BIRD; GUPTA, 2020, p. 175). E, como expressa Gnilka (1972, p. 285), a alegria contida nas cartas de Paulo, e nesta perícope $\mathrm{Fl} \mathrm{4,1-7} \mathrm{não} \mathrm{é}$ diferente, tem suas raízes na salvação obtida com Cristo.

Nutridos por esta confiança, e tendo a alegria como expressão presente

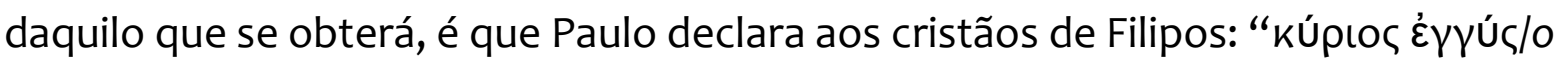
Senhor está próximo" (v.5c). Esta afirmação tem em si um sentido de presente e de futuro (CABRAL, 2015, p. 126). Bianchini (2010, p. 85) adverte que isto não significa que Paulo esteja pedindo para os filipenses viverem separados da realidade ou que ajam como se suas existências estivessem livres de dificuldades. Pelo contrário, pede que vivam e lutem com plena confiança na proximidade do Senhor, tanto em seu sentido escatológico, como em Rm 13,12; Tg 5,8; 1Pd 4,7; Ap 3,11, ou, como ao que se refere o SI 145,18 (LXX 144,18): "O Senhor está perto de todos os que o invocam".

Além disso, o apóstolo quer os cristãos de Filipos como homens e mulheres de bondade, voltados para o bem de todos, "magnânimos" (HAWTHORNE; MARTIN, 2004, p. 244), sendo esta característica um sinal que os distinga em meio aos demais (FOCANT, 2016, p. 268; ODEN, 2001, p. 339), cultivando e demonstrando sempre a generosidade e amabilidade para com todos (PITTA, 2010, p. 282; HENDRIKSEN, 2005, p. 579; PÉREZ MILLOS, 2016, p. 286).

Chamados a exercitar a oração como elemento unificador, vivendo a paz de Deus (v.6-7)

Os Filipenses são chamados a praticar a oração, "apresentando suas petições diante de Deus" (MARTIN, 2011, p. 170), tendo nela um elemento unificador, capaz de dar o equilibrium em todas as situações (HAWTHORNE; MARTIN, 2004, p. 245-246), porque na harmonia se manifesta a paz, visto que aquele que entra em oração com o Senhor, "entra na própria presença de Deus" (HENDRIKSEN, 2005, p. 531) e é capaz de colaborar para o bem comum, sem anularse, com serenidade (ODEN, 2001, p. 340), com sentimentos de gratidão e reconhecimento (FEE, 2004, p. 512; HOLLOWAY, 2017, p. 183).

Quando se tem paz se possui alegria, então, tudo está interligado e evidencia a união com Cristo, na ideia de uma paz de Deus "quase que personificada" (MARTIN, 2011, p. 171). Paulo indica a paz como a "fonte unificadora 
de tudo" (FOCANT, 2016, p, 270), capaz de irradiar-se para a vida de toda a comunidade, contagiando a todos em vista da harmonia entre eles (PÉREZ MILLOS, 2016, p. 281), uma vez que "a paz de Deus” é capaz de superar os conflitos humanos (FEE, 2004, p. 515). É isto que Paulo está propondo aos cristãos da comunidade de Filipos, para que eles possam tomar consciência de que a vida deles seja tomada como exemplo, e que isto se manifeste diante do próximo pois, como afirma o texto, eles devem permanecer firmes e em harmonia no Senhor (FEE, 2004, p. 495).

Neste sentido, Paulo apresenta à Igreja de Filipos a prática da oração como o instrumento com o qual os membros da comunidade podem superar suas diferenças e amenizar os seus conflitos, solidificando ainda mais os fundamentos da vida comunitária e da comunhão entre os irmãos e irmãs (PASTOR, 2005, p. 41). Como recorda Mazzarolo:

Importa orar para transformar a própria vida. Quando a prece é ouvida, a vida é transformada porque a prece é sincera. Assim, a oração seria um caminho para encontrar a alegria de viver e restabelecer os conflitos da comunidade (MAZZAROLO, 2011, p. 146).

De modo muito enfático, Paulo insiste apresentando as modalidades de como colocar-se diante do Senhor e, com a partícula adverbial " $\mu \eta \delta \grave{v} /$ não" ou "nem mesmo"

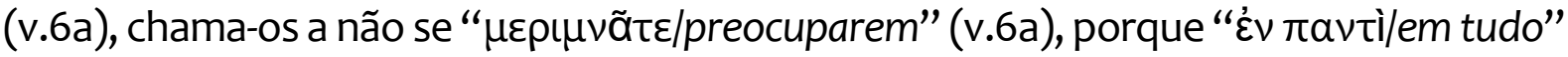

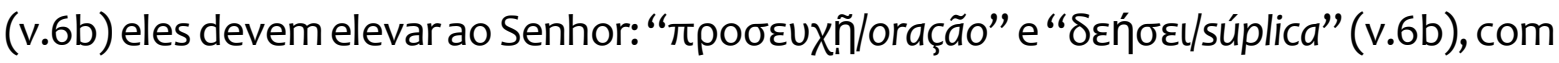

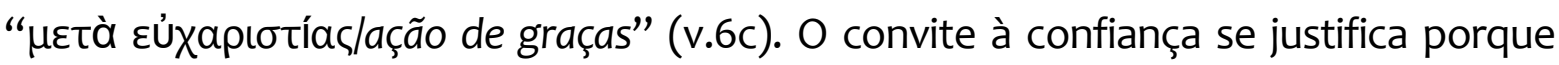
muitas deviam ser as inquietudes pelas quais os membros da comunidade de Filipos estavam passando: “pobreza, preocupações materiais e inseguridade” (FOCANT, 2016, p, 269), visto que "os tempos em que a Epístola foi escrita eram tempos difíceis para os cristãos" (PÉREZ MILLOS, 2016, p. 275).

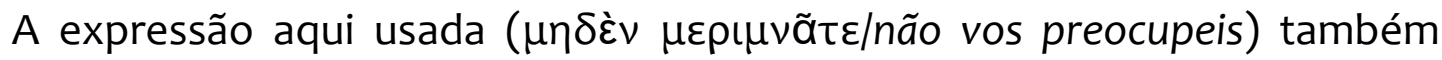
poderia ser traduzida por "não vos inquieteis", no sentido de trazer serenidade e paz (HENDRIKSEN, 2005, p. 581), ou ainda, no sentido de "não se deixar agitar por alguma coisa" (PITTA, 2010, p. 283) e de "permanecerem firmes no Senhor" (ODEN,

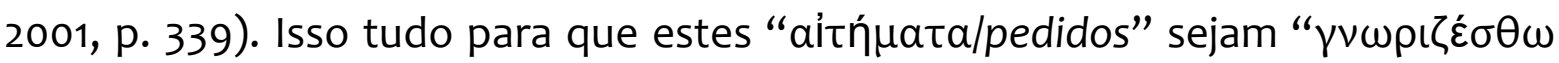

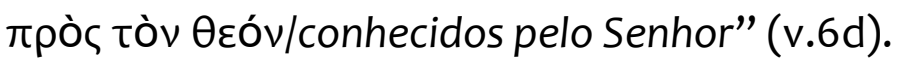


Isto não quer dizer que Deus não os conheça, mas servem para que eles possam expressar tal confiança, assim como esclarece O’Brien (1991, p. 498) ao dizer que "o efeito desse acúmulo de três substantivos sinônimos para a oração tem como função enfatizar a importância da oração na vida cristã, bem como da constância e a confiança". Mais ainda, "a oração alimenta a confiança no Senhor" (PITTA, 2010, p. 283). Como diz o salmista: "coloca tua alegria no Senhor e ele realizará os desejos de teu coração" (SI 37,4)

Consequentemente, Paulo não está fazendo da oração um subterfúgio e nem mesmo escondendo ou negando que, na vida de comunidade, haja situações conflituosas, mas que diante das preocupações, das realidades adversas e, principalmente, do que quebra a unidade, o cristão encontra apoio e sustento ao

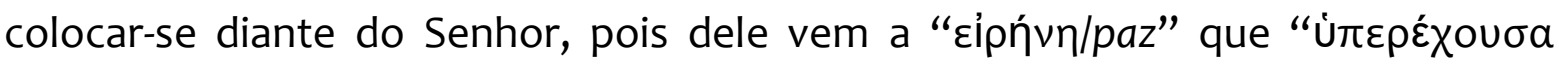

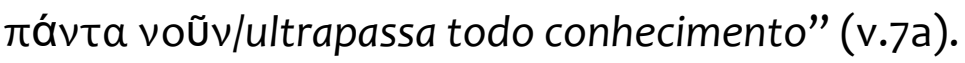

Concluindo a lista das exortações feitas nos vv.4-6, Paulo afirma que " $\dot{n}$

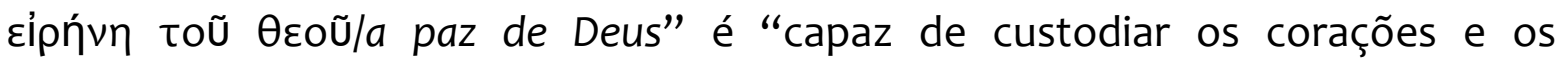
pensamentos dos destinatários em Cristo Jesus" (PITTA, 2010, p. 284). Apresentaa como "uma provisão divina capaz de superar as inquietudes" (PÉREZ MILLOS, 2016, p. 296), tendo sempre presente que a paz não significa ausência de conflitos. Ela é fruto e resultado da ação do Espírito Santo atuando na vida e docilidade dos cristãos, abertos à busca de soluções comuns. A paz faz isso, porque ela é capaz

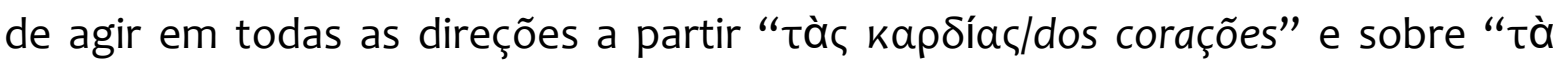

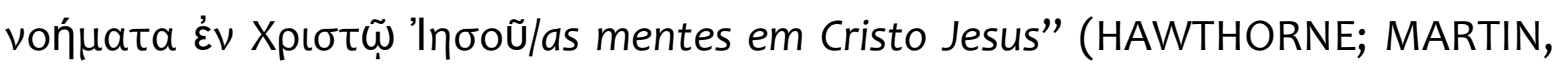
2004, p. 247).

\section{Aplicação pastoral}

Seja nas relações interpessoais, como nas relações familiares, e não de modo diferente nas relações comunitárias e pastorais na vida da Igreja, há o instinto primeiro, muitas vezes, de negar os conflitos ou de querer suprimi-los, e não de querer resolvê-los com maturidade e sinceridade. Isto ocorre, talvez, porque falte maturidade ou porque neste ambiente não reina a confiança e nem se busque resolver os conflitos com maturidade.

De modo muito tranquilo e exemplar, Paulo apresenta uma situação conflituosa e o faz amorosamente. Ele não põe a situação "debaixo do tapete"; 
pelo contrário, ele expõe o conflito e ajuda a pensar e refletir sobre a questão, mirando possíveis soluções. Como adverte Medina (2016, p. 384), ao propor à reconciliação, Paulo está convidando Evódia e Síntique e toda a comunidade ao amor e à disposição ao perdão e à superação dos conflitos, em Cristo Jesus.

A metodologia de Paulo, hoje e sempre, precisa ser retomada igualmente nas práticas pastorais e comunitárias, não tendo medo de advertir com caridade e de se interessar pelo bem da comunidade, assim como Paulo pediu de seu " $\gamma \nu \eta ́ \sigma \iota$

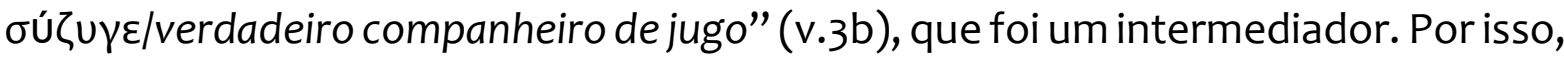
não é salutar quando, diante do conflito, reina a prática da fofoca, isto é, ao invés de dirigir-se à pessoa implicada na situação, comunica-se o fato a terceiros, que nada têm a ver com o assunto, ou ainda, quando se prefere manter para si, sem compartilhar. Isto com certeza faz muito mal a si e aos demais, pois a qualquer momento pode "estourar".

Outro detalhe na perícope de Fl 4,1-7 é o fato de que, mesmo diante do conflito, Paulo convida à alegria, como expressa o v.4: "Alegrai-vos sempre no Senhor! Novamente digo: alegrai-vos!" Como sentir-se alegre em meio aos problemas, às contrariedades, as desavenças e às intrigas comunitárias? Seria Paulo um homem tão aéreo e fora do mundo que teria perdido a noção da realidade? "Mǹ үर́voıto/de forma alguma!" Pois a alegria exigida aqui não é uma alegria momentânea, fruto dos eventos temporários, mas uma alegria que é fruto da certeza do amor de Cristo pelo ser humano.

Paulo está dizendo que, se Cristo deu sua vida por amor ao ser humano, toda dificuldade encontra Nele amparo e tira o peso das contrariedades. A alegria é resultado da confiança e da certeza de permanecer no Senhor.

Como Paulo resolveu o conflito? O texto não diz se o problema foi resolvido, se o intermediário no conflito conseguiu apaziguar os ânimos. A passagem não menciona se Paulo teve êxito em sua exortação. No entanto, mesmo que Paulo não tenha resolvido tudo, ele apresenta pistas para que um problema seja dirimido ou, pelo menos, amenizado, mas nunca negado ou encoberto.

Segundo Paulo, qualquer problema perde sua força diante da oração e da súplica, como evidencia o v.6: "não vos preocupeis, mas em toda oração e súplica, com ação de graça os pedidos vossos sejam conhecidos diante de Deus". Portanto, pessoalmente ou em comunidade, a primeira solução está em colocar-se em oração, isto é, confiar no Senhor, sendo sempre perseverante na busca de 
possíveis soluções e em conjunto, a partir do discernimento constante e perseverante (PÉREZ MILLOS, 2016, p. 294).

\section{Considerações finais}

Mesmo que o livro dos Atos dos Apóstolos apresente uma Igreja ideal ou que possa ser vista sem o devido espírito crítico, como uma Igreja perfeita e sem defeitos, isto não procede, como foi demonstrado pelo estudo da perícope de FI 4,1-7 e de tantos outros testemunhos que expõem as contrariedades e os antagonismos das primeiras comunidades cristãs.

Mas, mesmo que os conflitos sejam evidenciados, é preciso ter claro por que eles foram narrados. A partir desta explanação, a qual tomou como base a Carta de Paulo aos Filipenses, ainda cabe o questionamento: Por que Paulo apresenta o conflito destas duas mulheres? Por que ele as nomeia? Provavelmente, Paulo trouxe isso à tona porque o conflito ameaçava seriamente à unidade da Igreja e porque poderia servir de paradigma para se resolver outros e evitar conflitos ainda piores. Por esta razão, a referência e a necessidade de uma carta a ser lida para toda a Igreja.

Hansen (2009, p. 284) pensa que o fato de Paulo ter chamado uma terceira

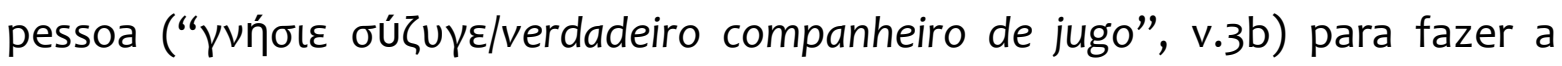
intervenção mostra quão profunda era a divisão entre essas duas mulheres (Evódia e Síntique, Fl 4,2), visto serem lideranças importante na vida da comunidade, e quão amplo era o impacto negativo de sua divisão na Igreja.

Outro elemento a ser destacado nestas considerações finais é o uso que Paulo fez dos termos que implicam a necessidade de se colocar diante do Senhor

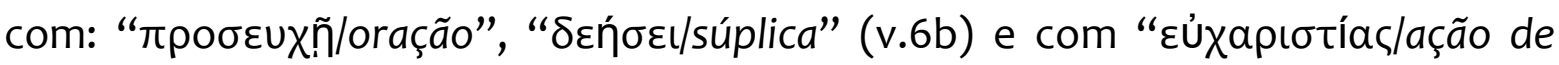
graças" (v.6c), como instrumentos para se retomar a harmonia. Mesmo que a repetição tenha caráter estilístico, as quais refletem sobre os três termos

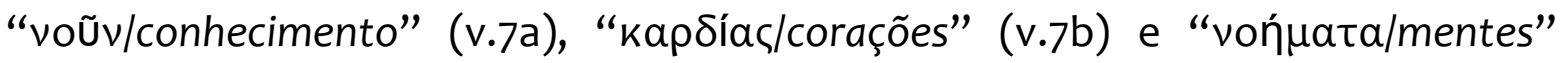
(v.7c), e estejam enfatizados pelas quatro indicações: " $\pi a ́ v \tau o \tau \varepsilon / s e m p r e " ~(v .4 a)$,

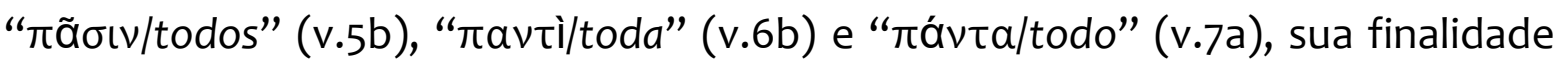
principal é evidenciar a confiança irrestrita no Senhor, que tudo sabe e tudo transforma. 
Portanto, mesmo que os conflitos se façam presentes - e muitas vezes são inevitáveis -, não são eles que determinam a vida da comunidade. Eles precisam ser enfrentados com serenidade e maturidade e não com polarizações e ofensas pessoais, que chegam a atingir e atacar a moral da outra pessoa como se tem presenciado no contexto hodierno, dentro e fora da vida comunitária eclesial.

\section{Referências}

BARTH, G. A Carta aos Filipenses. São Leopoldo: Sinodal, 1983.

BIANCHINI, F. Lettera ai Filippesi: Cinisella Balsamo: Edizioni San Paolo, 2010.

BIRD, M. F.; GUPTA, N. K. Philippians. Cambridge: Cambridge University Press, 2020.

CABRAL, E. Filipenses: A Humildade de Cristo como Exemplo para a lgreja. [S.I.]: CPAD-Casa Publicadora das Assembleias de Deus, 2015.

COUSAR, C. B. Reading Galatians, Philippians, and 1 Thessalonians: a literary and theological commentary. Georgia: Smyth \& Helwys Publishing, 2001.

CRADDOCK, F. B. Filippesi. Torino: Claudiniana, 2015.

FEE, G. D. Comentario de la Epístola a los Filipenses. Viladecavalls: CLIE, 2004.

FOCANT, C. La Carta a los Filipenses. Salamanca: Sígueme, 2016.

GNILKA, J. La lettera ai Filippesi. Brescia: Paideia, 1972.

GONZAGA, W. Os Conflitos na Igreja Primitiva entre Judaizantes e Gentios a partir das Cartas de Paulo aos Gálatas e aos Romanos. Santo André: Academia Cristã, 2015a.

GONZAGA, W. Os Conflitos na Igreja Primitiva entre Judaizantes e Gentios em GI 2. Santo André: Academia Cristã, 2015b.

GONZAGA, W. A Sagrada Escritura, a Alma da Sagrada Teologia. In: MAZZAROLO, I.; FERNANDES, L. A.; LIMA, M. de L. C. (Orgs.). Exegese, Teologia e Pastoral: relações, tensões e desafios. Rio de Janeiro: Editora PUC-Rio; Santo André, SP: Academia Cristã, 2015c. p. 201-235.

GONZAGA, W. O Corpus Paulinum no Cânon do Novo Testamento. Atualidade Teológica, Rio de Janeiro, v. 21, n. 55, p. 19-41, jan./abr. 2017.

HAHN, S.; MITCH, C. As cartas de São Paulo aos Filipenses, aos Colossenses e a Filêmon: Cadernos de estudo bíblico. São Paulo: ECCLESIAE, 2018.

HANSEN, G. W. The letter to the Philippians. Grand Rapids: Eerdmans; Nottingham, UK: APOLLOS, 2009. 
HAWTHORNE, G. F.; MARTIN, R. P. Philippians. Word Biblical Commentary, v. 43. [S.I.]: Zondervan, 2004.

HENDRIKSEN, W. Efésios e Filipenses. São Paulo: Cultura Cristã, 2005.

HOLLOWAY, P. A. Philippians. Hermeneia, v. 33B. Minneapolis: Fortress Press, 2017.

LLAGUNO, J. G. Diles que no se sigan por sola una parte de la Escritura, que miren otras: San Pablo y las mujeres. Sal terrae: Revista de teología pastoral, v. 96, n. 1127, p. 723-736, 2008.

LÓPEZ, E. E. Relevancia de las mujeres en las primeras comunidades cristianas. Misión Joven: Revista de Pastoral Juvenil, n. 508, p. 5-14, 2019.

MARTIN, R. P. Filipenses. São Paulo: Vida Nova, 2011.

MAZZAROLO, I. Carta de Paulo aos Filipenses. 2. ed. Rio de Janeiro: Mazzarolo Editor, 2011.

MEDINA, D. A. Reconciliación y paz. Un aporte desde la teología paulina. Análisis: revista colombiana de humanidades, v. 48, n. 89, p. 377-390, 2016.

NESTLÉ-ALAND. Novum Testamentum Graece. 28. ed. Revidierte Auflage. Stuttgart: Deutsche Bibelgesellschaft, 2012.

O'BRIEN, P. T. The Epistle to the Philippians. A commentary on the Greek Text. NIGNT. Michigan: William B. Eerdmans, 1991.

ODEN, T. C. Gálatas, Efesios, Filipenses. La Biblia Comentada por los Padres da Iglesia. Nuevo Testamento 8. Madrid: Ciudad Nueva, 2001.

PASTOR, F. Corpus Paulino II. Espanha: Desclée de Brouwer, 2005.

PENNA, R. Lettera ai Filippesi; Lettera a Filemone. Roma: Città Nuova, 2002.

PÉREZ MILLOS, S. Filipenses. Viladecavalls: CLIE, 2016.

PITTA, A. Lettera agli Filippesi. Roma: Paoline, 2010.

REUMANN, J. Philippians. The Acho Yale Bible, vol. 33B. New Haven and London: Yale University Press, 2008.

SCHLIER, H. La Lettera agli Filippesi. Brescia: Paideia, 1973.

SILVA, M. Philippians. Baker exegetical commentary on the New Testament. Grand Rapids, MI: Baker Academic, 2005.

TOMLIN, G. Filipenses e Colossenses. São Paulo: Cultura Cristã, 2015. 